\title{
BMJ Open Effect of Housing First on violence- related traumatic brain injury in adults with experiences of homelessness and mental illness: findings from the At Home/Chez Soi randomised trial, Toronto site
}

Cilia Mejia-Lancheros (10 ," James Lachaud (1) , , Vicky Stergiopoulos, ${ }^{2,3}$ Flora I. Matheson, ${ }^{1,4}$ Rosane Nisenbaum, ${ }^{1,5}$ Patricia O'Campo, ${ }^{1,5}$ Stephen W. Hwang ${ }^{1,6}$

To cite: Mejia-Lancheros C, Lachaud J, Stergiopoulos V, et al. Effect of Housing First on violence-related traumatic brain injury in adults with experiences of homelessness and mental illness: findings from the At Home/Chez Soi randomised trial, Toronto site. BMJ Open 2020;10:e038443. doi:10.1136/ bmjopen-2020-038443

- Prepublication history and additional material for this paper are available online. To view these files, please visit the journal online (http://dx.doi. org/10.1136/bmjopen-2018018426).

Received 11 March 2020 Revised 21 October 2020 Accepted 28 0ctober 2020

D) Check for updates

(c) Author(s) (or their employer(s)) 2020. Re-use permitted under CC BY-NC. No commercial re-use. See rights and permissions. Published by BMJ.

For numbered affiliations see end of article.

Correspondence to Dr Cilia Mejia-Lancheros; Cilia.Mejia-Lancheros@ unityhealth.to

\section{ABSTRACT}

Objectives People experiencing homelessness have a high prevalence and incidence of traumatic brain injury (TBI) due to violence. Little is known about the effectiveness of interventions to reduce TBI in this population. This study assessed the effect of Housing First (HF) on violence-related TBI in adults with experiences of homelessness and mental illness.

Design Pragmatic randomised trial.

Participants 381 participants in the Toronto site of the At Home/Chez randomised trial.

Intervention HF participants were provided with scattered-site housing using rent supplements and supports from assertive community treatment or intensive case management teams $(n=218,57.2 \%)$. Control participants had access to treatment as usual (TAU) in the community ( $n=163,42.8 \%)$.

Main outcome measures Primary outcomes were an incident physical violence-related TBI event and the number of physical violence-related TBI events during the follow-up period (January 2014 to March 2017). Intervalcensored survival time regression and zero-inflated negative binomial regression were used to assess the effect of HF on primary outcomes.

Results Among study participants, 9.2\% ( $n=35)$ had an incident physical violence-related TBI event, and the mean physical violence-related TBI events was 0.16 (SD \pm 0.6 ). Compared with TAU participants, HF participants did not have a significantly lower risk of an incident violence-related TBI event (adjusted HR : $0.58(95 \% \mathrm{Cl}$, 0.29 to 1.14)), but they had a significantly lower number of physical violence-related TBI events (unadjusted incidence rate ratio (IRR): $0.22(95 \% \mathrm{Cl}, 0.06$ to 0.78$)$; adjusted IRR: 0.15 (95\% Cl, 0.05 to 0.48$)$ ).

Conclusion HF may be a useful intervention to reduce the burden of TBI due to physical violence among homeless individuals with mental illness.

Trial registration number ISRCTN42520374.
Strengths and limitations of this study

- This is the first study to use a randomised design to assess the effect of a housing and support intervention on physical violence-related traumatic brain injury (TBI) events in individuals with experiences of homelessness and mental illness.

- An incident TBI event and the number of TBI events reported on an annual basis over a 2.5-year followup period were the primary analysed outcomes.

- TBI was assessed by self-report, and the specific dates on which TBls occurred were unknown.

- The interval-censored survival time regression was used to calculate the association between Housing First and an incident physical violence-related TBI event.

- Observed findings may not be generalisable to other settings.

\section{INTRODUCTION}

Traumatic brain injury (TBI) is an important health issue contributing to the high global burden of mortality, morbidity and disability. ${ }^{1-4}$ There were an estimated 27.08 million incident TBI cases and 55.50million prevalent TBI cases worldwide in 2016. ${ }^{1}$ Globally, TBI accounts for 8.1 million years of life lived with disability. ${ }^{1}$

TBI can have negative consequences for the health and well-being of individuals due to damage to specific brain areas and associated brain function. ${ }^{5-8}$ TBI is associated with mental disorders (eg, post-traumatic stress disorder, depression, anxiety, suicidality and cognitive disorders),${ }^{9-13}$ physical health disorders (neurological and endocrine dysfunction) 7810111314 and social behaviour deficits 
(eg, social interactions, social cognition, community integration, communication and adaptation, and criminal behaviour). ${ }^{12} 15-20$

TBI accounts for a high economic burden for patients and health systems ${ }^{21} 22$ and is more prevalent and incident in socioeconomically excluded populations such as incarcerated $^{23}$ and marginally housed individuals. ${ }^{24} 25$ A recent systematic review and meta-analysis of studies involving 11417 homeless and marginally housed individuals $^{25}$ found that $53.4 \%$ of this population group had experienced a TBI of any severity during their lifetime, and $24.9 \%$ of 6302 people, had suffered a moderateto-severe TBI event. TBI in individuals who experience homelessness may contribute to premature mortality, ${ }^{25} 26$ poor health status, alcohol and drug misuse $e^{25}$ and housing instability. 25283132

Housing First (HF) interventions offer access to housing without mental health or substance use treatment preconditions, together with mental health supportive services. ${ }^{33}$ HF has been implemented worldwide ${ }^{34} 35$ as a strategy to end homelessness and enhance health and well-being. $\mathrm{HF}$ is effective in providing long-term housing stability for people experiencing homelessness. ${ }^{36}$ As people experiencing homelessness are more exposed to violence and victimisation, ${ }^{3738}$ and violence is one of the leading causes of TBI in this population, ${ }^{39} 40$ it is important to assess the effects of $\mathrm{HF}$ on violence-related TBI in this population. To our knowledge, no previous randomised trial has evaluated the effects of an HF intervention on TBI in this population.

This study assessed the effect of an HF intervention on (1) an incident physical violence-related TBI over a 2-year follow-up period and (2) the number of physical violence-related TBI events among adults with experiences of homelessness and mental illness who participated in the Toronto site of the At Home/Chez Soi (AH/ CS) randomised trial.

\section{METHODS}

\section{Study population, design, setting and procedures}

This study included participants in the Toronto site of the $\mathrm{AH} / \mathrm{CS}$ pragmatic randomised trial carried out between October 2009 and March 2017. ${ }^{41}$ Detailed information regarding recruitment, randomisation, interventions and follow-up has been previously published. ${ }^{36} 41$ Briefly, participants in the Toronto site were recruited between 1 October 2009 and 31 July 2011 from shelters, drop-in centres, hospitals, outreach programmes and other supportive services available for homeless people in Toronto. The main inclusion criteria were (1) adults $\geq 18$ years; (2) absolutely homeless or precariously housed (defined as being housed in rooming house, or singleroom occupancy, or lodging in a hotel or motel with a history of two or more episodes of absolute homelessness in the previous year, or being homeless for at least 4 weeks in the previous year); and (3) having a diagnosable mental illness with or without a substance use disorder. ${ }^{3641}$
The AH/CS study was powered to detect an effect size of 0.5 between HF and treatment as usual (TAU) groups for the primary outcome of days of stable housing. ${ }^{36}$ At the Toronto site, 575 participants were stratified as either high needs (HN) or moderate needs (MN) for mental health services. The assessment of the level of need for mental health services was based on the following criteria: (1) the presence of a psychotic disorder or bipolar affective disorder with psychotic features (assessed with the Mini International Neuropsychiatric Interview, V.6.0), ${ }^{42}$ (2) community functioning ability (assessed with the Multnomah Community Ability Scale), ${ }^{43}$ (3) a history of mental health hospitalisations in the previous 5 years and (4) a history of incarceration in the previous 6 months. Participants classified as $\mathrm{HN}$ were randomised to $\mathrm{HF}$ with assertive community treatment (ACT) plus rent supplements (\$C600 per month) or to TAU. Randomisation of participants to the study's intervention groups was made using computer-based adaptive randomisation procedures at the study centre and electronically sent to the baseline interview's study team. ${ }^{36}{ }^{41}$ Participants classified as $\mathrm{MN}$ were randomised to $\mathrm{HF}$ with intensive case management (ICM) services plus rent supplement or to TAU. MN participants who identified as ethnoracial (non-white) and were randomised to the HF group were offered the option to receive either ethnoracial-specific ICM or standard ICM services. ${ }^{36} 41$ TAU participants received social, housing and health supports available in their local communities. Considering the nature of the study design and intervention, neither the study participants nor the study personnel were blinded to the HF intervention group assignment. Patients and the public were not involved in the design, conduct, reporting or dissemination plans of our research.

At the end of the 2-year follow-up period (phase 1), participants were asked to consent to continue their participation in the study for an additional 2 years (phase 2). Of the 575 participants initially enrolled in the study, 414 consented to participate in phase 2 and were followed up for an additional 2.46 years. Comparisons of the main characteristics of participants who participated in phase 2 of the study $(n=414)$ and those who did not $(n=161)$, as well as the number of participants assigned to the intervention groups are presented in online supplemental table 1 . Overall, $57 \%$ and $42 \%$ of participants in phase 2 received HF (ACT or ICM) and TAU, respectively. Participants in phase 2 had spent significantly more years homeless over their lifetime than those who did not participate in phase 2. No differences were observed between the two groups regarding age, gender, ethnoracial background, education level, mental disorders and number of physical comorbidities.

In this study, we included 381 (92\%) phase 2 participants who had information regarding violence-related TBI, the primary outcome of interest. There were no significant differences in the main characteristics of the group of participants included in this study $(\mathrm{n}=381)$ and those excluded $(n=33)$ (online supplemental table 2). 


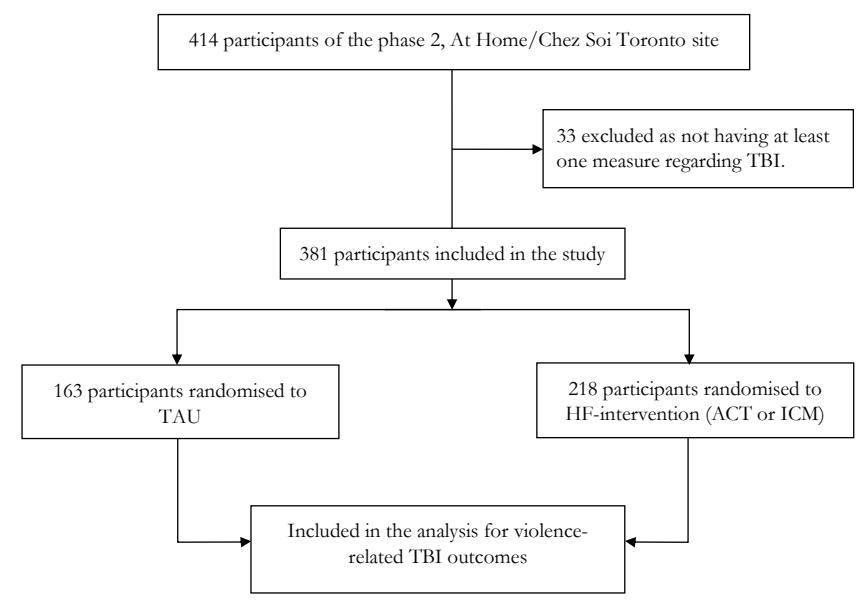

Figure 1 Study flowchart, participants of phase 2 of the At Home/Chez Soi study, Toronto site. ACT, assertive community treatment; HF, Housing First; ICM, intensive case management; TAU, treatment as usual; TBI, traumatic brain injury.

The flow diagram of the study sample is presented in figure 1 .

\section{Patient and public involvement}

The development of the study's main intervention (the HF model, with provision of immediate housing without preconditions and client choice as a guiding principle) occurred before the development of the study and was informed by the priorities and preferences of people experiencing chronic homelessness. Study participants were not involved in the development of the study design or choosing survey instruments used to measure the study outcomes. A group of people with lived experience of homelessness and/or mental health issues (the People with Lived Experience Caucus) provided advice to the research team during the first 2 years of the study. None of the Caucus members were study participants.

Patients or study participants were not involved in the recruitment or conduct of the $\mathrm{AH} / \mathrm{CS}$ study. Local community-based organisations that deliver social, housing and health supports for people experiencing homelessness were involved in the recruitment of participants. Three community-based agencies were involved in and responsible for delivering the HF intervention services (ICM or ACT) and administering the rent supplements that participants in the $\mathrm{HF}$ intervention group received.

The findings of the study have been and will continue to be made publicly available through online reports, blogs and media. Study participants were aware of the nature of the intervention (provision of housing with rent supplements and supports), which was considered a major benefit of participation in the trial.

\section{Intervention and outcomes}

HF (with ACT or ICM services plus rent supplements) was compared with TAU over the AH/CS phase 2 period (2-year follow-up). The two main outcomes were (1) the occurrence of an incident physical violence-related TBI (yes/no) and (2) the number (or frequency) of physical violence-related TBI events during the phase 2 follow-up period. Data on TBI events were collected during the phase 2 follow-up period but not during the phase 1 follow-up period. Information regarding self-reported TBI was obtained at annual face-to-face interviews using a survey instrument that included validated self-reported questions regarding experiences of TBI in people experiencing homelessness. ${ }^{2844}$ These self-reported TBI survey questions have been used in previous studies of homeless individuals in Canada and the USA. ${ }^{28} 44$ In this study, we included two questions regarding experiences of violence-related TBI ('I am going to ask you about injuries to your head and neck that you have had since the last interview (month, year): Since your last interview, have you injured your head or neck in a fight, from being hit by someone or from being shaken violently?') If the participant answered yes, they were asked how many times this occurred. This is due to the fact that homeless people are commonly victims of physical violence and assaults, ${ }^{37} 38$ which are leading causes of TBI in this population. ${ }^{39} 40$ Despite we also collected TBI events caused by transportation means, which could be an important cause of TBI; only 13 incident events happened in our phase 2 population over the 2-year follow-up, thereby being such a small sample for modelling a meaningful analysis. The distribution of an incident TBI event caused by transportation means is presented in online supplemental table 3 . There were no statistical differences in the percentage of participants who experienced a TBI event caused by transportation means between participants who received $\mathrm{HF}(\mathrm{n}=8$, $3.7 \%)$ and TAU $(n=5,3.1 \%)$, nor related to the level of need (HN, $\mathrm{n}=6,4.5 \% ; \mathrm{MN}, \mathrm{n}=7,2.8 \%)$ or ethnoracial background (non-white, $\mathrm{n}=5,7.3 \%$; white, $\mathrm{n}=8,9.8 \%$ ).

Level of need for mental health service ( $\mathrm{HN}$ and $\mathrm{MN}$ ) and ethnoracial backgound (non-white and white) were considered as adjusting covariates in the analyses, as they were study design variables.

\section{Statistical analysis}

We described the main baseline characteristics of the study population in the overall sample and across the HF intervention groups. We also calculated the frequency and percentage of having suffered an incident physical violence-related TBI and the number of those TBI events over the phase 2 follow-up period.

As we only knew that the TBI incident event occurred between the baseline date and the last interview, but not at the specific event date, we used the interval-censored 
survival time regression ${ }^{45}{ }^{46}$ with exponential distribution $^{47}$ to estimate the association between the HF intervention and an incident physical violence-related TBI. The unadjusted and adjusted interval-censored HRs and 95\% CIs were estimated. ${ }^{48}$ The level of need for mental health services (HN and MN) and the ethnoracial background (non-white, white) were included in the models to adjust for a potential effect of these two AH/CS study's design variables on the findings. To assess the effect of the HF intervention on the number of physical violencerelated TBI events, we used zero-inflated negative binomial regression that accounts for the excessive zeros and overdispersion $^{49}$ of this count-based outcome. An offset equal to the $\log$ of follow-up years was included in the models to account for the differential person-intervaltime in the study. Need levels and ethnoracial status were also included in the count component of the model. The $\mathrm{HF}$ intervention (HF vs TAU) was used to predict the excess of zeros in the non-count component of model. Incidence rate ratios (IRRs) and 95\% CI were estimated for the outcome of the number of TBI events.

All the analyses were performed by intention-to-treat using Stata V.16. ${ }^{48} 50$

\section{RESULTS}

The characteristics of the study participants $(n=381)$ are presented in table 1. Participants were on average 40.6 (SD, 11.7) years old, with $68.0 \%$ and $57.2 \%$ being men and a member of a non-white ethnoracial background, respectively. Among all participants, $57.2 \%$ received $\mathrm{HF}$ (ACT or ICM), and $34.7 \%$ had a high level of need for mental health services. More than half of the participants had $\geq 3$ years of lifetime homelessness $(55.3 \%)$ and $\geq 3$ comorbidities $(71.9 \%)$. They also had a high prevalence of alcohol use disorders $(44.6 \%)$ and drug use disorders $(48.8 \%)$. These characteristics were similarly distributed across study groups (TAU/HF) (table 1).

The median follow-up time for participants of the Toronto AH/CS trial during phase 2 of the study was 1.84 years (IQR: $1.84-1.88$ ), with a maximum of 2.46 years. Participants in the HF group had a lower percentage of incident TBI $(n=15,6.9 \%)$ caused by physical violencerelated events compared with participants in the TAU group $(n=20,12.3 \%)$ over the study period (table 2$)$. Participants with a high need for mental health services had a higher percentage $(12.12 \%)$ of an incident TBI caused by a physical violent-related event than participants with a moderate level of need for mental health services $(7.6 \%)$ (table 2 ). White participants had a significantly higher percentage $(14.1 \%)$ of an incident physical violence-related TBI event than non-white participants $(5.5 \%)$.

The distribution of the number of violence-related TBI events in the overall study sample $(\mathrm{N}=381)$ and for the $\mathrm{HF}$ vs TAU groups is presented in table 3 . There were 35 TBIs caused by physical violence-related events among all participants. The frequency of the number of these TBI events was higher in the TAU group (mean $0.26( \pm 0.9)$ ) than in the HF group (mean $0.09( \pm 0.3)$ ). There were 346 participants without any physical violence-related TBIs.

In the unadjusted and adjusted interval-censored survival time analyses, compared with the TAU, there were no significant associations between $\mathrm{HF}$ and risk of an incident physical violence-related TBI-unadjusted results (HF vs TAU, HR: 0.55 (95\% CI, 0.28 to 1.07); P value $=0.079)$ (table 4); adjusted results, HR: 0.58 (95\% CI, 0.29 to 1.14 ), $\mathrm{P}$ value $=0.113$ ) (table 4 ). The graphical representation of survival without an incident physical violence-related TBI event between the study groups is presented in figure 2. It was observed that participants from a non-white background had a lower risk of an incident physical violence-related TBI event than those from a white ethnoracial background (adjusted HR: 0.40 (95\% CI, 0.20 to 0.82$)$; $\mathrm{P}$ value $=0.012)$ (table 4 ).

Regarding the risk of experiencing a lower number of physical violence-related TBI events, the unadjusted analysis identified that the HF group had an incidence rate 0.22 times lower for the number of physical violencerelated TBI events than the TAU group (IRR $0.22(95 \%$ CI, 0.06 to 0.78$), P$ value $=0.020)($ table 5 , model 1$)$. When adjusting the analysis for the level of need and ethnoracial status, participants in the HF group had an incident rate 0.15 times lower for the number of physical violencerelated TBI events than the TAU group (HF vs TAU, adjusted IRR: 0.15 (95\% CI, 0.05 to 0.48 ), $\mathrm{P}$ value $=0.020$ ) (table 5, model 2). The non-white ethnoracial background participants tended to have a lower incident rate for the number of physical violence-related TBI events, being marginally significant (non-white vs white, adjusted IRR: 0.501 (95\% CI, 0.244 to 1.029 ), P value $=0.060$ ). It was also observed that HF decreased the likelihood of zero number of physical violence-related TBI events (model 2, zero-inflated component).

\section{DISCUSSION}

This is the first study to assess the effect of HF on an incident TBI and the number (or frequency) of TBI events due to physical violence-related events in individuals with experiences of homelessness and mental illness. We found that $9.2 \%$ of our sample self-reported an incident physical violence-related TBI event during a period of about 2 years. While this finding is based on self-reported data that could be affected by recall or memory problems, it is consistent with previous studies that found that violence-related exposures or events such as assault, intimate partner violence and self-inflicted violence are major causes of TBI in homeless people. ${ }^{39}{ }^{40}$ We found that HF did not significantly reduce the probability of suffering an incident physical violence-related TBI over the 2-year follow-up period. However, HF participants had a significantly lower risk of experiencing a higher number of physical violence-related TBI events.

Reducing the risk of TBI events is challenging, particularly when the risk of violence is associated with a variety 
Table 1 Demographic and clinical characteristics of study participants randomised to TAU or HF

\begin{tabular}{|c|c|c|c|c|c|}
\hline \multirow[b]{2}{*}{ Main characteristics } & \multicolumn{2}{|c|}{ Overall study sample $(n=381)$} & \multirow{2}{*}{$\begin{array}{l}\text { TAU }(n=163) \\
\% \text { or mean }( \pm S D)\end{array}$} & \multirow{2}{*}{$\begin{array}{l}\text { HF }(n=218) \\
\% \text { or mean }( \pm S D)\end{array}$} & \multirow[b]{2}{*}{$P$ value } \\
\hline & $\mathbf{n}$ & $\%$ or mean $( \pm S D)$ & & & \\
\hline \multicolumn{6}{|l|}{ Randomisation group } \\
\hline HF (ACT or ICM) & 218 & 57.2 & & & \\
\hline \multicolumn{6}{|l|}{ Level of needs } \\
\hline High needs & 132 & 34.7 & 36 & 33 & \\
\hline \multicolumn{6}{|l|}{ Ethnoracial group } \\
\hline White & 163 & 42.8 & 46 & 40 & 0.270 \\
\hline Non-white & 218 & 57.2 & 54 & 60 & \\
\hline Age in years & 381 & $40.6(11.7)$ & $41.15(11.9)$ & $40.20(11.5)$ & 0.434 \\
\hline \multicolumn{6}{|c|}{ Lifetime homelessness } \\
\hline$<3$ years & 163 & 44.7 & 44.2 & 45.0 & 0.869 \\
\hline$\geq 3$ years & 202 & 55.3 & 55.8 & 55.0 & \\
\hline \multicolumn{6}{|l|}{ Education level } \\
\hline $\begin{array}{l}\text { Low education level } \\
\text { (completed up to } \\
\text { high school) }\end{array}$ & 240 & 64.9 & 64.1 & 65.4 & 0.793 \\
\hline $\begin{array}{l}\text { High educational } \\
\text { level (attended/ } \\
\text { completed college, } \\
\text { trade school or } \\
\text { university) }\end{array}$ & 130 & 35.1 & 35.9 & 34.6 & \\
\hline \multicolumn{6}{|c|}{ Drug abuse or dependence disorder } \\
\hline No & 195 & 51.2 & 52.2 & 50.5 & 0.744 \\
\hline Yes & 186 & 48.8 & 47.9 & 49.5 & \\
\hline \multicolumn{6}{|c|}{ Alcohol abuse or dependence disorder } \\
\hline No & 211 & 55.4 & 52.8 & 57.3 & 0.374 \\
\hline Yes & 170 & 44.6 & 47.2 & 42.7 & \\
\hline \multicolumn{6}{|c|}{ Number of physical chronic comorbidities $†$} \\
\hline$<3$ & 242 & 63.5 & 62.6 & 64.2 & 0.742 \\
\hline$\geq 3$ & 139 & 36.5 & 37.4 & 35.8 & \\
\hline
\end{tabular}

${ }^{*}$ Current major depressive episode, current manic episode or hypomanic episode, post-traumatic stress disorder, current panic disorder, mood disorder with psychotic features, suicidality and psychotic disorder.

†Asthma, chronic bronchitis or emphysema, stroke, heart disease, Alzheimer disease or dementia, arthritis, stomach or intestine ulcer, Crohn's disease or colitis, kidney or bladder problems, hypertension, diabetes, thyroids problems, liver disease, cancer, iron anaemia, tuberculosis, HIV/AIDS and migraine

ACT, assertive community treatment; HF, Housing First; ICM, intensive case management; TAU, treatment as usual.

of factors such as substance use, poverty and exclusion. $^{5152}$ Effective interventions and policies to reduce the risk of TBI among people experiencing homelessness are needed, ${ }^{37}$ and the provision of housing is a promising approach to achieve this goal. By providing immediate access to permanent housing without preconditions, HF can reduce chronic exposure to street and shelter environments where individuals have a higher 
Table 2 Incident physical violence-related TBI in adults with experiences of homelessness and mental illness participating in phase 2 follow-up of the At Home/Chez Soi study, Toronto site

\begin{tabular}{|c|c|c|c|c|c|c|}
\hline & \multicolumn{5}{|c|}{ Incident violence-related TBI } & \multirow[b]{3}{*}{$P$ value } \\
\hline & \multirow{2}{*}{$\begin{array}{l}\text { Overall sample } n=381 \\
n\end{array}$} & \multicolumn{2}{|c|}{$\begin{array}{l}\text { No, } n=346 \\
(90.8 \%)\end{array}$} & \multicolumn{2}{|c|}{$\begin{array}{l}\text { Yes, } n=35 \\
(9.2 \%)\end{array}$} & \\
\hline & & $\mathbf{n}$ & $\%$ & $\mathbf{n}$ & $\%$ & \\
\hline Years of follow-up, median (IQR) & $1.84(1.84-2.46)$ & & & & & \\
\hline Intervention group & 381 & & & & & \\
\hline TAU & 163 & 143 & 87.73 & 20 & 12.3 & 0.072 \\
\hline $\mathrm{HF}(\mathrm{ACT} / \mathrm{ICM})$ & 218 & 203 & 93.12 & 15 & 6.9 & \\
\hline Difference: HF vs TAU & & & & -5 & -5.39 & \\
\hline Level of needs & 381 & & & & & \\
\hline $\mathrm{MN}$ & 249 & 230 & 92.37 & 19 & 7.6 & 0.149 \\
\hline $\mathrm{HN}$ & 132 & 116 & 87.88 & 16 & 12.12 & \\
\hline Difference: $H N$ vs $M N$ & & & & -3 & 4 & \\
\hline Ethnoracial group & 381 & & & & & \\
\hline White & 163 & 140 & 85.89 & 23 & 14.1 & 0.004 \\
\hline Non-white & 218 & 206 & 94.5 & 12 & 5.5 & \\
\hline Difference: Non-white vs white & & & & -11 & -8.61 & \\
\hline
\end{tabular}

${ }^{*} A$ head traumatic injury related to physical violence events (fight, hit by someone or shaken violently).

$+\chi^{2}$ test.

ACT, assertive community treatment; HF, Housing First; HN, high needs; ICM, intensive case management; MN, moderate needs; TAU, treatment as usual; TBI, traumatic brain injury.

likelihood of either becoming the victims of violence or engaging in activities that increase the risk of violence. ${ }^{53}$ HF may also contribute to reducing the number of physical violence-related TBI events by facilitating access to mental health services that may reduce the experience of violence-related TBI to mental health problems.
Given the pervasive stigma attached to mental illness, ${ }^{54}$ people with mental disorders are often targets of interpersonal violence as they are perceived as dangerous. ${ }^{556}$ Some individuals with unmanaged or untreated mental disorders may also be more likely to engage in violent or criminal-linked behaviours, ${ }^{55} 57$ increasing their risk of

Table 3 Distribution of the number of violence-related TBI events in the overall study sample and according to HF treatment group in adults with experiences of homelessness and mental disorders participating in phase 2 follow-up of the At Home/ Chez Soi study, Toronto site

\begin{tabular}{|c|c|c|c|c|c|c|c|c|c|}
\hline & \multicolumn{8}{|c|}{ Number of violence-related $\mathrm{TBI}^{*}$} & \multirow[b]{3}{*}{$P$ value } \\
\hline & \multirow{2}{*}{\multicolumn{2}{|c|}{$\begin{array}{l}\text { Overall sample } \\
(n=381)\end{array}$}} & \multicolumn{6}{|c|}{ HF intervention group } & \\
\hline & & & \multicolumn{3}{|l|}{ TAU (n=163) } & \multicolumn{3}{|c|}{ HF treatment $(\mathrm{ACT} / \mathrm{ICM})(\mathrm{n}=218)$} & \\
\hline$n(\%)$ of TBls & \multicolumn{2}{|c|}{$35(9.2)$} & \multicolumn{3}{|l|}{$20(12.3)$} & \multicolumn{3}{|l|}{$15(6.9)$} & \\
\hline Mean $( \pm S D)$ & \multicolumn{2}{|c|}{$0.16(0.6)$} & \multicolumn{3}{|l|}{$0.26(0.9)$} & \multicolumn{3}{|l|}{$0.09(0.3)$} & $0.062^{*}$ \\
\hline Count of TBI & $\mathrm{n}$ & $\%$ & Count of TBI & $\mathrm{n}$ & $\%$ & Count of TBI & $\mathrm{n}$ & $\%$ & \\
\hline 0 & 346 & 90.8 & 0 & 143 & 87.7 & 0 & 203 & 93.1 & $0.211 \dagger$ \\
\hline 1 & 24 & 6.3 & 1 & 12 & 7.4 & 1 & 12 & 5.5 & \\
\hline 2 & 5 & 1.3 & 2 & 3 & 1.8 & 2 & 2 & 0.9 & \\
\hline 3 & 2 & 0.5 & 3 & 1 & 0.6 & 3 & 1 & 0.5 & \\
\hline 4 & 2 & 0.5 & 4 & 2 & 1.2 & 4 & 0 & 0.0 & \\
\hline 7 & 2 & 0.5 & 7 & 2 & 1.2 & 7 & 0 & 0.0 & \\
\hline
\end{tabular}

${ }^{*} \mathrm{~A}$ head traumatic injury related to physical violence events (fight, hit by someone or shaken violently).

†Fisher's exact test.

¥Wilcoxon rank-sum test.

$\mathrm{ACT}$, assertive community treatment; HF, Housing First; ICM, intensive case management; TAU, treatment as usual; TBI, traumatic brain injury. 
Table 4 Unadjusted and adjusted HR of an incident physical violence-related TBI in adults with experiences of homelessness and mental illness participating in phase 2 follow-up of the At Home/Chez Soi study, Toronto site

\begin{tabular}{llcl}
\hline & \multicolumn{2}{c}{ An incident violence-related TBI $(\mathbf{n}=\mathbf{3 5})^{*}$} & P value \\
\cline { 2 - 3 } & HR & $\mathbf{9 5 \% ~} \mathbf{~ l}$ \\
\hline $\begin{array}{l}\text { Model 1 (Unadjusted model) } \\
\text { HF treatment (vs TAU) }\end{array}$ & 0.55 & 0.28 to 1.07 & 0.079 \\
\hline $\begin{array}{l}\text { Model 2 (Adjusted model) } \\
\text { HF treatment (vs TAU) }\end{array}$ & 0.58 & 0.29 to 1.14 & 0.114 \\
$\begin{array}{l}\text { High needs (vs moderate } \\
\text { needs) }\end{array}$ & 1.44 & 0.73 to 2.84 & 0.292 \\
$\begin{array}{l}\text { Non-white ethnoracial } \\
\text { background (vs white) }\end{array}$ & 0.40 & 0.20 to 0.82 & 0.012 \\
\hline
\end{tabular}

${ }^{*}$ A head traumatic injury related to physical violence events (fight, hit by someone or shaken violently).

HF, Housing First; TAU, treatment as usual; TBI, traumatic brain injury.

interpersonal violence. Thus, promoting comprehensive mental health services and enhancing access to appropriate treatment for mental and substance use disorders can contribute to violence reduction. ${ }^{55}$

$\mathrm{HF}$ alone cannot address the multidimensional unmet need faced by people experiencing both homelessness and mental illness. However, HF-based programmes and other programmes (ie, outreach services, shelter services, social services) serving homeless populations ${ }^{58}$ offer the opportunity to access additional health services and social supports to further enhance housing stability and violence-related victimisation and behaviour mitigation, and therefore reduce prevalent adverse health outcomes such as TBI.

This study found that non-white participants had a lower risk of experiencing an incident TBI caused by physical violence-related events than white participants. In a previous study of homeless people in Toronto, white men had a significantly higher prevalence of TBI

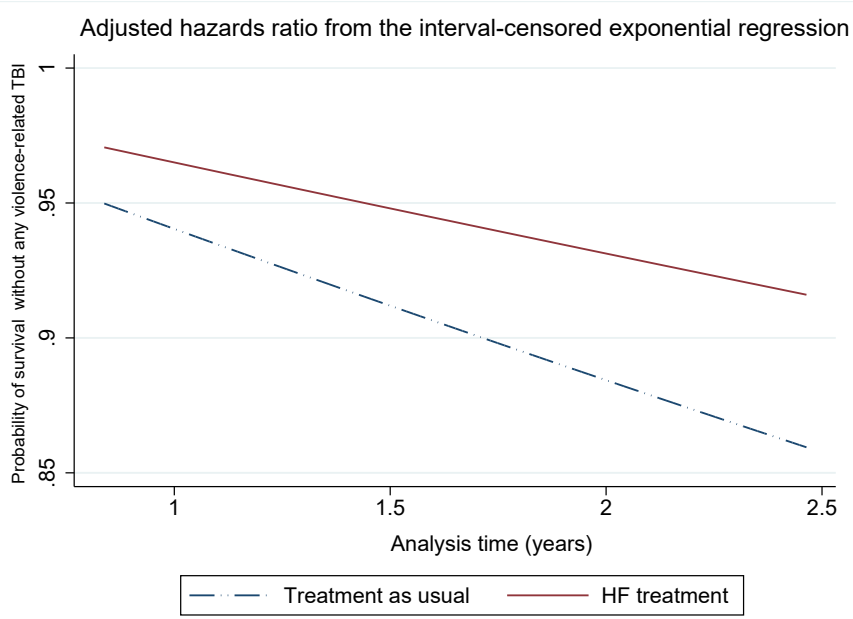

Figure 2 Survival without an incident physical violencerelated $\mathrm{TBI}$ event for participants who received $\mathrm{HF}$ and those received treatment as usual during phase 2 of the At Home/ Chez Soi study, Toronto site. HF, Housing First; TBI, traumatic brain injury. than non-white individuals. ${ }^{28}$ In contrast, a study of the US general population using validated TBI clinical scales found no significant differences in the rate of TBI between white and non-white individuals. ${ }^{59} \mathrm{~A}$ further US-based study that compared white and non-white population groups found that the rates of TBI-related deaths among white people significantly increased from 2007 to 2017 than among non-white individuals. ${ }^{60}$ Possible explanations for the ethnoracial differences observed in our study may include differences in the individual risk factors ${ }^{61}$ and systemic forces that lead to homelessness among non-white vs white individuals, or differential rates of recall of TBI.

This study has certain limitations. First, questions to assess TBI were administered during phase 2 but not phase 1 of the AH/CS study. Thus, we could not ascertain whether the protective effect we found was also present during phase 1 of the study. Furthermore, self-reported TBI data could be affected by recall bias or memory problems. This possibility needs to be considered when comparing results with those of other studies. In addition, this study only assessed the overall self-reported occurrence of physical violencerelated TBI events and not their severity or clinical significance using validated clinical instruments or medical diagnosis. Also, by using a non-clinical instrument or a more specific clinical criteria (eg, lose of consciousness, confusion, post-traumatic amnesia or other clinical symptoms such as emotional, mood and behavioural changes) to define the TBI event in this study, it is likely that some of the TBI events that participants reported did not actually constitute a clinical or a serious TBI event. This limited the possibility to explore the effects of $\mathrm{HF}$ on preventing or reducing more severe and clinically significant TBI events. Thus, studies using clinical data (medical records, brain imagines and clinical TBI scales) or more specific clinical criteria are required to build further evidence on this topic. Finally, the study findings may not be generalisable to other settings with different socioeconomic and health system characteristics or to homeless people without serious mental health disorders. 
Table 5 IRR for the number of physical violence-related traumatic brain injury events in adults with experiences of homelessness and mental illness participating in phase 2 follow-up of the At Home/Chez Soi study, Toronto site

\begin{tabular}{|c|c|c|c|}
\hline Number of physical violence-related head injuries $(n=35)^{\star}$ & IRR & $95 \% \mathrm{Cl}$ & $P$ value \\
\hline \multicolumn{4}{|l|}{ Model $1 †$ (unadjusted model) } \\
\hline \multicolumn{4}{|l|}{ Count component } \\
\hline HF treatment (vs TAU) & 0.216 & 0.059 to 0.784 & 0.020 \\
\hline In(time of follow-up in years) & \multicolumn{2}{|c|}{1 (exposure) } & \\
\hline Zero-inflated component & Coefficient & $95 \% \mathrm{Cl}$ & $P$ value \\
\hline HF treatment (vs TAU) & -4.197 & -6.331 to -2.062 & $<0.001$ \\
\hline Model2‡(adjusted model) & IRR & $95 \% \mathrm{Cl}$ & $P$ value \\
\hline \multicolumn{4}{|l|}{ Count component } \\
\hline HF treatment (vs TAU) & 0.152 & 0.049 to 0.476 & 0.001 \\
\hline High needs (vs moderate needs) & 1.405 & 0.597 to 3.306 & 0.437 \\
\hline Non-white (vs white) ethnoracial background & 0.501 & 0.244 to 1.029 & 0.060 \\
\hline In(time of follow-up in years) & \multicolumn{2}{|c|}{1 (exposure) } & \\
\hline Zero-inflated component† & Coefficient & $95 \% \mathrm{Cl}$ & $P$ value \\
\hline HF treatment (vs TAU) & -4.589 & -6.003 to -3.175 & $<0.001$ \\
\hline
\end{tabular}

*Head traumatic injury related to physical violence events (fight, hit by someone or shaken violently).

†Lnalpha=log-coefficient: 1.727 (0.603 to 2.851), $\mathrm{P}$ value $=0.003$.

fLnalpha=log-coefficient: 1.519 (0.575 to 2.463), $P$ value $=0.002$.

HF, Housing First; IRR, incidence rate ratio; TAU, treatment as usual.

Our study findings have a number of implications for social and health practice, research and policy. People experiencing homelessness have a disproportionate burden of TBI, which causes detrimental health and social sequelae ${ }^{25}$; thus, examining the impact of interventions such as HF in preventing TBI is instrumental in gaining an understanding of the full effects of such interventions and their potential impact on preventing and reducing poor health outcomes. Our findings highlight the need to integrate community-based, mental health-based and harm reduction-based support services such as HF as an effective strategy to not only improve the housing stability of this population ${ }^{36}$ but also to reduce exposure to preventable TBI risks such as violence. Furthermore, HF services should be considered when providing care to homeless or unstably housed individuals who have a history of TBI or are at high risk of TBI. Future research should examine the effect of HF on incident TBI using administrative or medical record data to inform the development of effective interventions to reduce the sequelae of TBI in homeless populations.

\section{CONCLUSION}

HF with mental health support services and rent supplements may be a useful intervention to reduce the burden of TBI due to physical violence among homeless individuals with mental illness.

\section{Author affiliations}

${ }^{1}$ MAP Centre for Urban Health Solutions, Li Ka Shing Knowledge Institute, St Michael's Hospital, Unity Health Toronto, Toronto, Ontario, Canada
${ }^{2}$ Department of Psychiatry, University of Toronto, Toronto, Ontario, Canada ${ }^{3}$ Centre for Addiction and Mental Health, Toronto, Ontario, Canada ${ }^{4}$ Centre for Criminology and Sociolegal Studies, University of Toronto, Toronto, Ontario, Canada

${ }^{5}$ Dalla Lana School of Public Health, University of Toronto, Toronto, Ontario, Canada ${ }^{6}$ Division of General Internal Medicine, Department of Medicine, University of Toronto, Toronto, Ontario, Canada

Acknowledgements We thank At Home/Chez Soi (AH/CS) study participants for their participation in the study. We also thank the AH/CS project team, site coordinators and service providers who have contributed to the design, implementation and follow-up of participants.

Contributors CM-L, JL and SWH conceptualised the study. CM-L was responsible for the methodological analysis approach of the study, carried out the statistical analysis and the first interpretation of the study findings and wrote the first manuscript version. $J \mathrm{~L}$ and $\mathrm{RN}$ contributed to the validation of the statistical analysis, the first interpretation of the results and the critical revision of the first manuscript version. VS, FM, PO and SWH provided important intellectual contributions in the interpretation of the findings and edition of the final version of the manuscript. VS, PO and SWH are also the co-principal investigators of the Toronto side of the At Home/Chez Soi study. All co-authors revised and approved the final version of the paper and are accountable for all aspects of the work.

Funding The Toronto site of the At Home/Chez Soi study was funded by the Mental Health Commission of Canada (Grant number: NA), Ontario Ministry of Health and Long-Term Care (HSRF \#259) and the Canadian Institute of Health Research (ClHR MOP-130405). This study also received funding from St Michael's Hospital Research Training Centre Scholarship awarded (RTC-2019-scholarship) to Dr Cilia Mejia-Lancheros. The funding institutions had no role in the study design, collection, analysis and interpretation of the data, or in the preparation, revision or approval of the present manuscript. Thus, the views expressed in this publication are the views of the authors.

Competing interests None declared.

Patient consent for publication Not required.

Ethics approval The Toronto site At Home/Chez Soi study (phase 1 and phase 2) received ethics approval (REB no.: 09-208) from the Research Ethics Board at 
St Michael's Hospital (Toronto, Canada). All participants provided written informed consent to participate in the study.

Provenance and peer review Not commissioned; externally peer reviewed.

Data availability statement Data are available upon reasonable request. The At Home/Chez Soi (AH/CS) study data set of the Toronto site, cannot be made publicly available due to the sensitive nature of the data and agreements and procedures governing the use of the data set that were established by the study sponsor, the Mental Health Commission of Canada. However, anonymised participant data from the AH/CS study, as well as the specific data set used in the present paper, can be made available to investigators who complete the following steps: (1) present a study proposal that has received approval from an independent research committee or research ethics board; (2) provide a data request for review by the AH/CS data access committee; and (3) following approval of the request, execute a datasharing agreement between the investigators and the AH/CS data custodians. Study proposals and data access requests should be sent to Evie Gogosis (Evie.Gogosis@ unityhealth.to), research manager for the Toronto site of the AH/CS study, and to $\mathrm{Dr}$ Stephen Hwang (Stephen.Hwang@unityhealth.to), co-principal investigator of the Toronto site of the AH/CS study.

Supplemental material This content has been supplied by the author(s). It has not been vetted by BMJ Publishing Group Limited (BMJ) and may not have been peer-reviewed. Any opinions or recommendations discussed are solely those of the author(s) and are not endorsed by BMJ. BMJ disclaims all liability and responsibility arising from any reliance placed on the content. Where the content includes any translated material, BMJ does not warrant the accuracy and reliability of the translations (including but not limited to local regulations, clinical guidelines, terminology, drug names and drug dosages), and is not responsible for any error and/or omissions arising from translation and adaptation or otherwise.

Open access This is an open access article distributed in accordance with the Creative Commons Attribution Non Commercial (CC BY-NC 4.0) license, which permits others to distribute, remix, adapt, build upon this work non-commercially, and license their derivative works on different terms, provided the original work is properly cited, appropriate credit is given, any changes made indicated, and the use is non-commercial. See: http://creativecommons.org/licenses/by-nc/4.0/.

\section{ORCID iDs}

Cilia Mejia-Lancheros http://orcid.org/0000-0003-1131-8439

James Lachaud http://orcid.org/0000-0001-8498-8922

\section{REFERENCES}

1 James SL, Theadom A, Ellenbogen RG, et al. Global, regional, and national burden of traumatic brain injury and spinal cord injury, 1990-2016: a systematic analysis for the global burden of disease study 2016. Lancet Neurol 2019;18:56-87.

2 Badhiwala JH, Wilson JR, Fehlings MG. Global burden of traumatic brain and spinal cord injury. Lancet Neurol 2019;18:24-5.

3 Dewan MC, Rattani A, Gupta S, et al. Estimating the global incidence of traumatic brain injury. J Neurosurg 2019;130:1080-97.

4 Nguyen R, Fiest KM, McChesney J, et al. The International incidence of traumatic brain injury: a systematic review and meta-analysis. Can J Neurol Sci 2016;43:774-85.

5 Prins M, Greco T, Alexander D, et al. The pathophysiology of traumatic brain injury at a glance. Dis Model Mech 2013;6:1307-15.

6 Kinoshita K. Traumatic brain injury: pathophysiology for neurocritical care. J Intensive Care 2016;4:1-10.

7 Pavlovic D, Pekic S, Stojanovic M, et al. Traumatic brain injury: neuropathological, neurocognitive and neurobehavioral sequelae. Pituitary 2019;22:270-82.

8 Ramos-Cejudo J, Wisniewski T, Marmar C, et al. Traumatic brain injury and Alzheimer's disease: the cerebrovascular link. EBioMedicine 2018;28:21-30.

9 Dreer LE, Tang X, Nakase-Richardson R, et al. Suicide and traumatic brain injury: a review by clinical researchers from the National Institute for disability and independent living rehabilitation research (NIDILRR) and Veterans health administration traumatic brain injury model systems. Curr Opin Psychol 2018;22:73-8.

10 Kaplan GB, Leite-Morris KA, Wang L, et al. Pathophysiological bases of comorbidity: traumatic brain injury and post-traumatic stress disorder. J Neurotrauma 2018;35:210-25.

11 Mollayeva T, D'Souza A, Mollayeva S. Sleep and psychiatric disorders in persons with mild traumatic brain injury. Curr Psychiatry Rep 2017;19:47.
12 Stéfan A, Mathé J-F, et al, SOFMER group. What are the disruptive symptoms of behavioral disorders after traumatic brain injury? A systematic review leading to recommendations for good practices. Ann Phys Rehabil Med 2016:59:5-17.

13 Elder GA, Ehrlich ME, Gandy S. Relationship of traumatic brain injury to chronic mental health problems and dementia in military veterans. Neurosci Lett 2019;707:134294.

14 Immonen R, Harris NG, Wright D, et al. Imaging biomarkers of epileptogenecity after traumatic brain injury - Preclinical frontiers. Neurobiol Dis 2019;123:75-85.

15 Ilie G, Cusimano MD, Li W. Prosodic processing post traumatic brain injury - a systematic review. Syst Rev 2017;6:1.

16 Semple BD, Zamani A, Rayner G, et al. Affective, neurocognitive and psychosocial disorders associated with traumatic brain injury and post-traumatic epilepsy. Neurobiol Dis 2019;123:27-41.

17 Osborne-Crowley K, McDonald S. A review of social disinhibition after traumatic brain injury. J Neuropsychol 2018;12:176-99.

18 May M, Milders M, Downey B, et al. Social behavior and impairments in social cognition following traumatic brain injury. J Int Neuropsychol Soc 2017:23:400-11.

19 Williams WH, Chitsabesan P, Fazel S, et al. Traumatic brain injury: a potential cause of violent crime? Lancet Psychiatry 2018;5:836-44.

20 Schofield PW, Malacova E, Preen DB, et al. Does traumatic brain injury lead to criminality? A whole-population retrospective cohort study using linked data. PLoS One 2015;10:e0132558-12.

21 Humphreys I, Wood RL, Phillips CJ, et al. The costs of traumatic brain injury: a literature review. Clinicoecon Outcomes Res 2013;5:281-7.

22 Kayani NA, Homan S, Yun S, et al. Health and economic burden of traumatic brain injury: Missouri, 2001-2005. Public Health Rep 2009;124:551-60.

23 Farrer TJ, Hedges DW. Prevalence of traumatic brain injury in incarcerated groups compared to the general population: a meta-analysis. Prog Neuropsychopharmacol Biol Psychiatry 2011;35:390-4.

24 Topolovec-Vranic J, Ennis N, Colantonio A, et al. Traumatic brain injury among people who are homeless: a systematic review. BMC Public Health 2012;12:1059.

25 Stubbs JL, Thornton AE, Sevick JM, et al. Traumatic brain injury in homeless and marginally housed individuals: a systematic review and meta-analysis. Lancet Public Health 2020;5:e19-32.

26 McMillan TM, Laurie M, Oddy $M$, et al. Head injury and mortality in the homeless. J Neurotrauma 2015;32:116-9.

27 Topolovec-Vranic J, Schuler A, Gozdzik A, et al. The high burden of traumatic brain injury and comorbidities amongst homeless adults with mental illness. J Psychiatr Res 2017;87:53-60.

28 Hwang SW, Colantonio A, Chiu S, et al. The effect of traumatic brain injury on the health of homeless people. CMAJ 2008;179:779-84

29 Schmitt T, Thornton AE, Rawtaer I, et al. Traumatic brain injury in a community-based cohort of homeless and Vulnerably housed individuals. J Neurotrauma 2017;34:3301-10.

30 Andersen J, Kot N, Ennis N, et al. Traumatic brain injury and cognitive impairment in men who are homeless. Disabil Rehabil 2014;36:2210-5.

31 Nikoo M, Gadermann A, To MJ, et al. Incidence and associated risk factors of traumatic brain injury in a cohort of homeless and vulnerably housed adults in 3 Canadian cities. J Head Trauma Rehabil 2017;32:E19-26.

32 Bacciardi S, Maremmani AGI, Nikoo N, et al. Is bipolar disorder associated with tramautic brain injury in the homeless? Riv Psichiatr 2017;52:40-6.

33 Tsemberis S. The pathways model to end homelessness for people with mental illness and addiction. Minneapolis, United States: Hazelden Information \& Educational Services, 2015.

34 Busch-Geertsema V. Housing first Europe. final report. Bremen, Brussels, 2013. Available: www.socialstyrelsen.dk/ housingfirsteurope

35 Goering PN, Streiner DL, Adair C, et al. The at Home/Chez Soi trial protocol: a pragmatic, multi-site, randomised controlled trial of a housing first intervention for homeless individuals with mental illness in five Canadian cities. BMJ Open 2011;1:e000323.

36 Stergiopoulos V, Mejia-Lancheros C, Nisenbaum R, et al. Long-Term effects of rent supplements and mental health support services on housing and health outcomes of homeless adults with mental illness: extension study of the at Home/Chez Soi randomised controlled trial. Lancet Psychiatry 2019;6:915-25.

37 Hsieh E. Surviving violence in everyday life: a communicative approach to homelessness. Soc Work Public Health 2017;32:110-21.

38 Latalova K, Kamaradova D, Prasko J. Violent victimization of adult patients with severe mental illness: a systematic review. Neuropsychiatr Dis Treat 2014;10:1925-39. 
39 Barnes SM, Russell LM, Hostetter TA, et al. Characteristics of traumatic brain injuries sustained among Veterans seeking homeless services. J Health Care Poor Underserved 2015;26:92-105.

40 Topolovec-Vranic J, Ennis N, Howatt M, et al. Traumatic brain injury among men in an urban homeless shelter: observational study of rates and mechanisms of injury. CMAJ Open 2014;2:E69-76.

41 Hwang SW, Stergiopoulos V, O'Campo P, et al. Ending homelessness among people with mental illness: the at Home/Chez Soi randomized trial of a housing first intervention in Toronto. BMC Public Health 2012;12:787.

42 Sheehan DV, Lecrubier Y, Sheehan KH, et al. The Mini-International neuropsychiatric interview (M.I.N.I.): the development and validation of a structured diagnostic psychiatric interview for DSM-IV and ICD10. J Clin Psychiatry 1998;59 Suppl 20:22-33.

43 Barker S, Barron N, McFarland BH, et al. A community ability scale for chronically mentally ill consumers: Part II. applications. Community Ment Health J 1994;30:459-72.

44 Waldmann CA. Traumatic brain injury (TBI). In: O'Connell J, ed. The health of homeless persons: a manual of communicable disease and common problems in shelters and on the streets. Boston, MA Boston Health Care for the Homeless Program and and the National Health Care for the Homeless Council, 2004: 237-41.

45 Sun J. The statistical analysis of Interval-censored failure time data. New York, NY: Springer, 2006.

46 Zhang Z, Sun J. Interval censoring. Stat Methods Med Res 2010:19:53-70.

47 Zhang Z. Parametric regression model for survival data: Weibul regression model as an example. Ann Trans/ Med 2016;4:484

48 StataCorp LLC. stintreg - Parametric models for interval-censored survival-time data. In: Survival analysis reference manual. College Station, Texas: Stata Press, 2019: 468.

49 Yang S, Harlow LL, Puggioni G, et al. A comparison of different methods of zero-inflated data analysis and an application in health surveys. J Mod App Stat Meth 2017;16:518-43.
50 StataCorp. Stata statistical software: release 16, 2019.

51 Muggah R. Researching the urban dilemma: urbanization, poverty and violence. Ottawa, Canada, 2012. Available: http://www.iadb.org/ intal/intalcdi/PE/2012/12203.pdf

52 Apraxine P, Duquenne A, Fetta S, et al. Urban violence and humanitarian challenges: joint report. Brussels, 2012.

53 Ellsworth JT. Street crime victimization among homeless adults: a review of the literature. Vict Offender 2019;14:96-118.

54 Mejia-Lancheros C, Lachaud J, O'Campo P, et al. Trajectories and mental health-related predictors of perceived discrimination and stigma among homeless adults with mental illness. PLoS One 2020;15:e0229385

55 Rueve ME, Welton RS. Violence and mental illness. Psychiatry 2008:5:34-48.

56 Seeman N, Tang S, Brown AD, et al. World survey of mental illness stigma. J Affect Disord 2016;190:115-21.

57 Labrum T, Simonsson P, Solomon PL. Stigma contributes to the risk of violence by persons with mental illness. J Psychosoc Rehabil Ment Health 2018;5:209-12.

58 Canadian Institute for Health Information. Improving the Health of Canadians: Mental Health and Homelessness. Ottawa, Canada: $\mathrm{CIHI}$, 2007.

59 Sharma R, Johnson A, Li J, et al. Racial disparities and the acute management of severe blunt traumatic brain injury. Trauma Surg Acute Care Open 2019;4:e000358.

60 Daugherty J, Waltzman D, Kelly Sarmiento ;, et al. Morbidity and mortality Weekly report traumatic brain injury-related deaths by Race/Ethnicity, sex, intent, and mechanism of Injury-United states, 2000-2017. Morb Mortal Wkly Rep Trauma 2019;68:1050-6.

61 Jasinski JL, Wesely JK, Mustaine E, et al. The Experience of Violence in the Lives of Homeless Women : A Research Report, 2005. 